\title{
Políticas Públicas e fragilidades na gestão de Unidades de Conservação Urbanas no Brasil
}

\section{Public Policies and management weaknesses in Urban Areas of Conservation in Brazil}

\begin{abstract}
Políticas Públicas y debilidades en la gestión de las Unidades de Conservación Urbanas en Brasil
\end{abstract}

Helder Pereira de Figueiredo ${ }^{1}$ Michel Constantino ${ }^{2}$ João Henrique de Souza Barros ${ }^{3}$ Reginaldo Brito Costa ${ }^{4}$

\author{
${ }^{1}$ Doutor em Ciências Ambientais e Sustentabilidade \\ Agropecuária pela Universidade Católica Dom Bosco (UCDB). \\ E-mail: hpfigueiredo@ipcms.com.br
}

2 Doutor em Economia. Professor no Programa de Pós-graduação em Ciências Ambientais e Sustentabilidade Agropecuária (UCDB).

E-mail: michel@ucdb.br

${ }^{3}$ Doutorando do Programa de Pós-graduação em Ciências Ambientais e Sustentabilidade Agropecuária (UCDB). E-mail: barros.jhs@gmail.com

${ }^{4}$ Doutor em Ciências Florestais. Professor no Programa de Pós-graduação em Ciências Ambientais e Sustentabilidade Agropecuária (UCDB).

E-mail: reg.brito.costa@gmail.com 
Resumo: O objetivo deste estudo foi caracterizar algumas Áreas de Proteção Ambiental (APAs) urbanas no Brasil, analisando as políticas públicas vinculadas ao planejamento urbano, passivos ambientais e fragilidades dessas políticas públicas em face da ocupação urbana. Foram checadas diferentes fontes de informação relacionadas às APAs urbanas analisadas, abrangendo planos de manejo, diagnósticos ambientais, artigos publicados e legislação aplicável. Constatou-se que os objetivos da criação das APAs, no que se refere a garantir a proteção dos ecossistemas e suas diversidades biológicas, disciplinar a ocupação do solo e o de possibilitar o uso sustentável dos recursos naturais, em sua plenitude, não têm sido atendidos em vários aspectos relacionados às necessidades humanas nas cidades e no seu entorno rural.

Palavras-chave: Áreas de Proteção Ambiental; recursos naturais; usos sustentáveis.

\begin{abstract}
The goal of this study was to characterize some urban Environmental Protection Areas (APAs) in Brazil, analyzing public policies related to urban planning, environmental liabilities and weaknesses of these policies due to urban occupation. Different sources were checked for information related to the urban APAs analyzed, including management plans, environmental diagnostics, published articles and applicable laws. It was found that the purpose of creating APAs, aiming to ensure protection of ecosystems and their biological diversity, regulate land use and to allow sustainable use of natural resources, have not been fully met in various aspects related to human needs in cities and its rural surroundings.
\end{abstract}

Key words: Environmental Protection Areas; natural resources; sustainable uses.

Resumen: El objetivo de este estudio fue caracterizar algunas Áreas de Protección Ambiental (APAs) urbanas en Brasil, el análisis de las políticas públicas relacionadas con la planificación urbana, los pasivos ambientales y debilidades de estas políticas em vista de la ocupación urbana. Se verificaron diversas fuentes de información relacionadas con las APPs urbanas analizadas, incluidos los planes de gestión, diagnósticos ambientales, artículos publicados y la legislación aplicable. Se encontró que los objetivos de la creación de APPs, en lo que respecta a garantizar la protección de los ecosistemas y su diversidad biológica, regular el uso de la tierra y para permitir el uso sostenible de los recursos naturales, en su totalidad, no se han cumplido en diversos aspectos relacionados con las necesidades humanas en las ciudades y su entorno rural.

Palabras clave: Áreas de Protección Ambiental; recursos naturales; usos sostenibles. 


\section{INTRODUÇÃO}

Em decorrência do crescimento populacional e pressão dos programas de desenvolvimento sobre as florestas tropicais, savanas e áreas úmidas, o Brasil, apesar de possuir expressiva riqueza em recursos naturais, vem sofrendo uma perda significativa de sua biodiversidade, o que se constitui como uma ameaça à integridade biológica dos ecossistemas. A ocupação de áreas naturais por aglomerados urbanos, normalmente ocasiona impactos sobre a vegetação remanescente, com perdas significativas em áreas bioprodutivas de água, especialmente se constituírem nascentes, com sérias implicações no abastecimento das cidades.

Para a proteção dessas áreas, foram instituídas alternativas tais como a criação das Unidades de Conservação (UCs), regulamentadas pela Lei 9.985 de 18 de julho de 2000, que institui o Sistema Nacional de Unidades de Conservação da Natureza (SNUC). Existem diversas modalidades de UCs no Brasil, dentre as quais estão as Áreas de Preservação Ambiental (APAs), que se tipificam como unidades de conservação de uso sustentável, objetivando compatibilizar o uso dos recursos naturais com a capacidade de suporte desses ambientes.

As UCs, portanto, são espaços territoriais que, pelas características biofísicas singulares ou outras qualidades e potencialidades socioculturais, merecem receber do Estado proteção efetiva e permanente através de regimes especiais de administração que Ihes garantam a integridade física sem perda das suas características e valores, mediante utilização de acordo com esses objetivos e manejo adequado.

Unidades de conservação localizadas em áreas urbanas estão mais sujeitas a intervenções antrópicas de impacto ambiental criminoso, como desmatamento, caça ilegal, extrativismo predatório, introdução de espécies exóticas, lançamento de águas servidas sem tratamento, deposição de resíduos sólidos urbanos dentro e nas áreas 
de borda, dentre outras, o que demanda estratégias bem elaboradas de monitoramento e fiscalização, principalmente em APAs que contenham mananciais de abastecimento de água à população.

As relações de natureza global remetem invariavelmente para a necessidade de produção que possa gerar mais qualidade de vida, especialmente no que se refere à alimentação humana e animal. Em decorrência, ambientes florestais outrora de matriz contínua associada à água têm sido fragmentados de forma consistente.

No Brasil, foram instituídos, em momentos distintos, instrumentos jurídicos que puderam respaldar as limitações de uso eventualmente impostas às propriedades localizadas nas áreas circundantes das unidades de conservação. No entanto a integridade ambiental dessas áreas é, muitas vezes, ameaçada por atividades econômicas e sociais, sobretudo no âmbito de áreas urbanas. É imperativo que a gestão dessas áreas alcance políticas e instrumentos de planejamento urbano e gestão ambiental e territorial.

Nesse cenário, o presente estudo objetivou realizar uma caracterização de algumas Áreas de Proteção Ambiental Urbanas no Brasil, em relação às políticas públicas vinculadas ao planejamento urbano, passivos ambientais e fragilidades das políticas públicas em face da ocupação urbana.

Para a consecução do objetivo, foram checadas diferentes fontes de informação relacionadas às APAs urbanas analisadas, abrangendo planos de manejo, diagnósticos ambientais, artigos publicados e legislação aplicável.

\section{2 ÁREAS DE PROTEÇÃO AMBIENTAL E A PRESERVAÇÃO DOS RECURSOS AMBIENTAIS}

As Unidades de Conservação abrangem dois grandes grupos de diferentes categorias de proteção ambiental: a) Unidades de Proteção 
Integral (UPI), cujo objetivo é preservar a natureza, sendo permitido apenas o uso indireto dos seus recursos naturais, admitindo-se exceções previstas em lei; b) Unidades de Uso Sustentável, cujo objetivo é o de compatibilizar a conservação da natureza com o uso sustentável de parcela de seus recursos naturais, tais como fauna, flora, solo e recursos hídricos, abrangendo sete tipos distintos, dentre as quais: Áreas de Relevante Interesse Ecológico (ARIE), Florestas Nacionais (FLONA), Reservas Extrativistas (RESEX), Reservas de Fauna (REF), Reservas de Desenvolvimento Sustentável (RDS), Reservas Particulares do Patrimônio Natural (RPPN) e as Áreas de Proteção Ambiental (APAs). Essas áreas podem apenas ter uso sustentável, ou seja, seu acesso, ocupação e exploração devem ser controlados para não prejudicar o ecossistema da área, que podem ter posse e domínios público ou privado (BRASIL, 2000).

Cabe aos órgãos governamentais a fiscalização da ocupação e exploração dessas áreas, tendo como finalidades principais: i) Garantir a proteção dos ecossistemas e suas diversidades biológicas; ii) disciplinar a ocupação do solo; iii) possibilitar o uso sustentável dos recursos naturais (solo, água e vegetação).

A instituição das Áreas de Proteção Ambiental (APAs) no Brasil consiste em um avanço das preocupações dos entes públicos com os cuidados ambientais, especialmente nas áreas onde há relevância efetiva para a população. O aumento demográfico em áreas urbanas, salvo raras exceções, conduz invariavelmente a agressões ao ambiente, muitas vezes expondo a riscos demasiados à biodiversidade, incluindo a própria vida humana.

Cabe salientar que perturbações ambientais nas áreas de proteção produzem efeitos indesejáveis decorrentes do uso e ocupação do solo das áreas de entorno dos mananciais hídricos (CHAVES; SANTOS, 2009). 


\subsection{Fragmentos florestais e os recursos hídricos}

A exploração intensa e seletiva de madeira, mudanças no uso da terra pelo agronegócio e ocupação urbana são os principais fatores responsáveis pela perda na diversidade de espécies arbóreas. Junto com o agravamento do processo de degradação ambiental e esgotamento dos recursos naturais disponíveis no planeta (especialmente água), nota-se um substancial crescimento da preocupação com os danos ambientais causados à reprodução e diversidade genética das espécies arbóreas (COSTA et al., 2015).

As florestas tropicais, que no passado ocupavam grandes extensões contínuas, atualmente encontram-se na forma de pequenos e dispersos fragmentos. Esses fragmentos podem dar a impressão inicial de que ainda existe uma amostra de uma comunidade original de espécies ameaçadas que irá se perpetuar, porém uma espécie pode estar efetivamente extinta há anos, antes da morte do último indivíduo (COSTA et al., 2015).

A perda da cobertura florestal, associada à sua fragmentação, representa uma grande ameaça à biodiversidade. No caso de espécies arbóreas, a alteração na abundância de polinizadores, dispersores, predadores e patógenos altera as taxas de recrutamento de plântulas; e os incêndios e mudanças microclimáticas, que atingem de forma mais intensa as bordas dos fragmentos, alteram as taxas de mortalidade das árvores (VIANA; PINHEIRO, 1998). Essa realidade não é exclusiva de ecossistemas rurais, mas também dos fragmentos florestais urbanos remanescentes.

O avanço da fragmentação em florestas nativas e os impactos causados pela ação antrópica, seja rural ou urbana, têm produzido fragmentos florestais cada vez mais isolados e menores, com maiores pressões em suas áreas de bordadura, o que acarreta perda da biodiversidade, recursos naturais e das interações biológicas (COSTA; 
SCARIOT, 2003; ROCHA, 2006). Dentre essas interações, estão aquelas entre plantas e insetos, que fazem parte dos maiores grupos de organismos e que dependem diretamente da disponibilidade dos recursos naturais presentes nas florestas que estão sendo transformadas (SCHOONHOVEN; JERMY; LOON, 1998). As pressões dos efeitos de borda estão intimamente relacionadas aos efeitos indesejáveis para os recursos hídricos principalmente para aquelas de áreas urbanas mais densamente povoadas.

A variabilidade genética pode exercer papel decisivo na sobrevivência das espécies quando há alteração repentina do ambiente, tal como decorrentes das mudanças climáticas globais, e passarão a ter cada vez mais participação significativa como agente determinante do sucesso das ações de restauração ecológica (GUIDUGLI, 2011). Quando apresentam base genética estreita, ou seja, pouca variabilidade genética, os indivíduos de uma espécie serão certamente mais sensíveis a pragas, doenças e estresses ambientais, tendo menores chances futuras de sobrevivência (ELLSTRAND; ELAM, 1993).

O geoprocessamento constitui-se em uma ferramenta importante nos estudos ambientais, associado ao monitoramento de áreas naturais e urbanas com fragmentos florestais remanescentes e água de superfície, seja em matas ciliares ou nascentes.

A técnica permite o desenvolvimento de análise integrada do ambiente, proporcionando um entendimento de áreas em estudo, diagnosticando consequências de ações antrópicas em escala local e global. Ab'Saber (2003) já enfatizava que a paisagem é sempre uma herança de processos fisiográficos e biológicos do patrimônio coletivo dos povos, ou seja, estes herdaram paisagens pelas quais deveriam ser responsáveis, valorizando os recursos naturais. 


\section{FRAGILIDADES DAS POLÍTICAS PÚBLICAS E PASSIVOS AMBIENTAIS EM ÁREAS DE PRESERVAÇÃO AMBIENTAL URBANAS}

Para efeito de uma visualização um pouco mais ampla de aspectos gerais associados a passivos ambientais, apresenta-se, no Quadro 1, breve caracterização de algumas Áreas de Proteção Ambiental Urbanas no Brasil, sinopse da APA, políticas públicas relacionadas ao planejamento urbano, passivos ambientais e fragilidade das políticas públicas em face de ocupação urbana. 


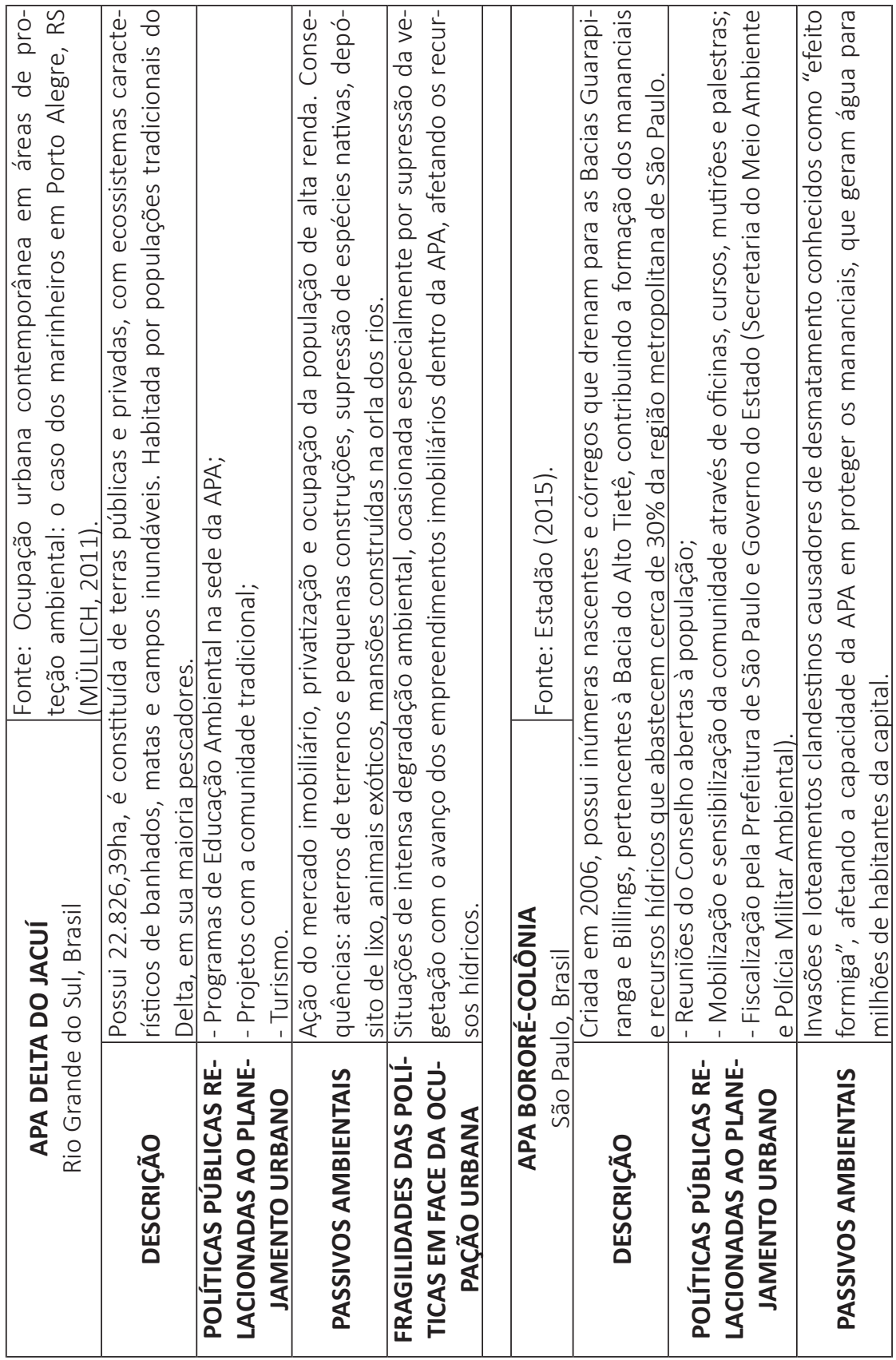




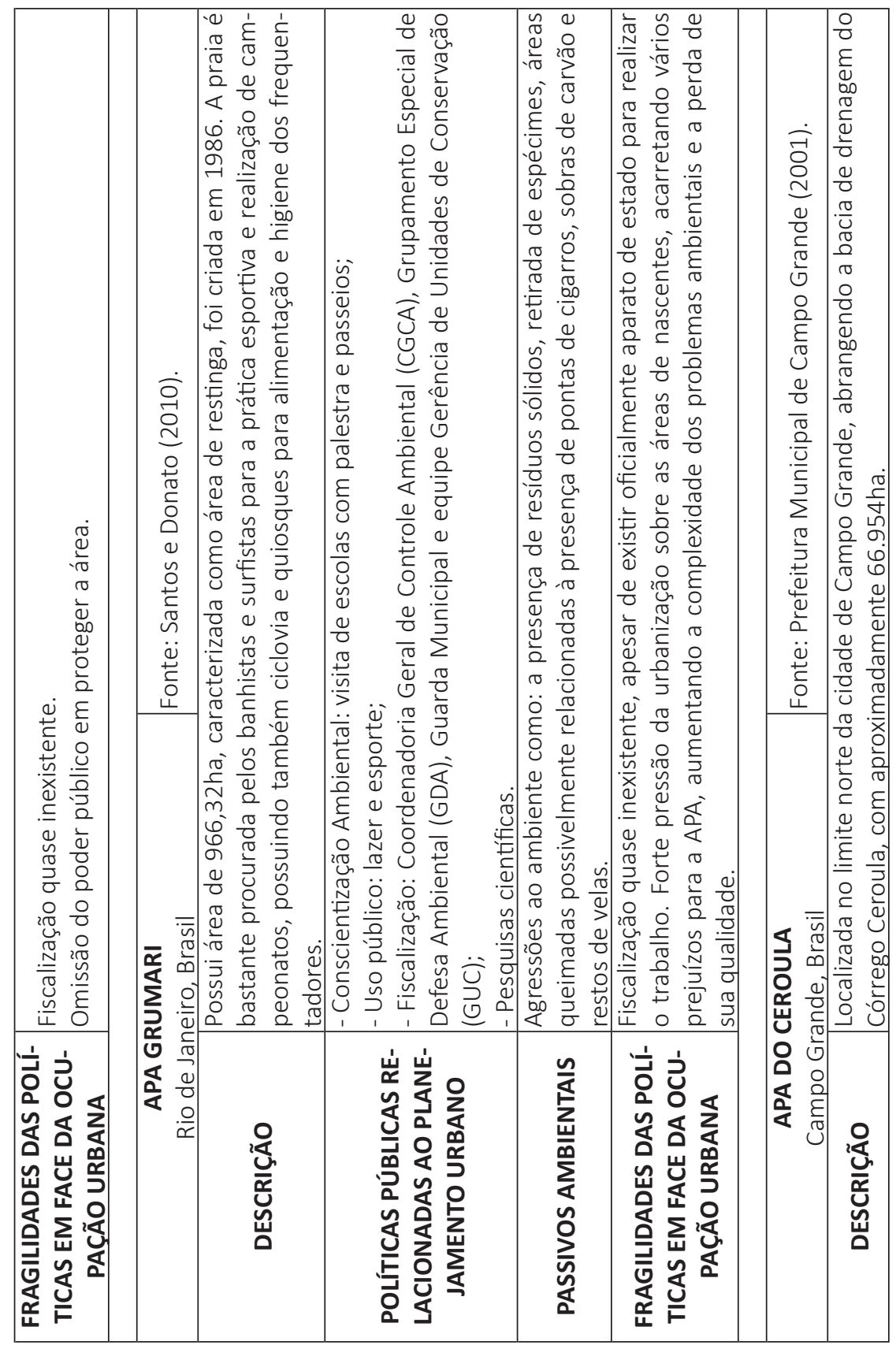




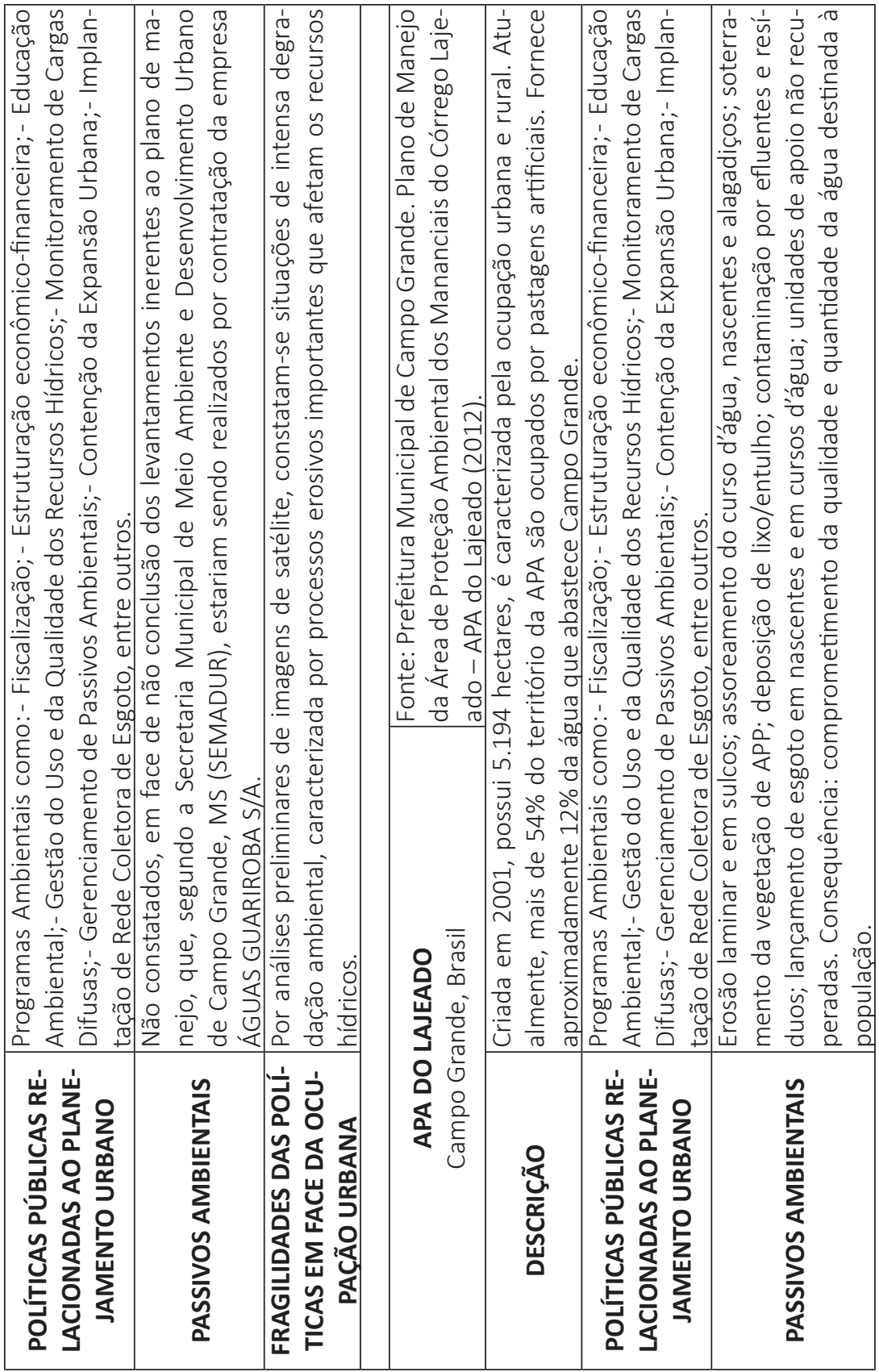




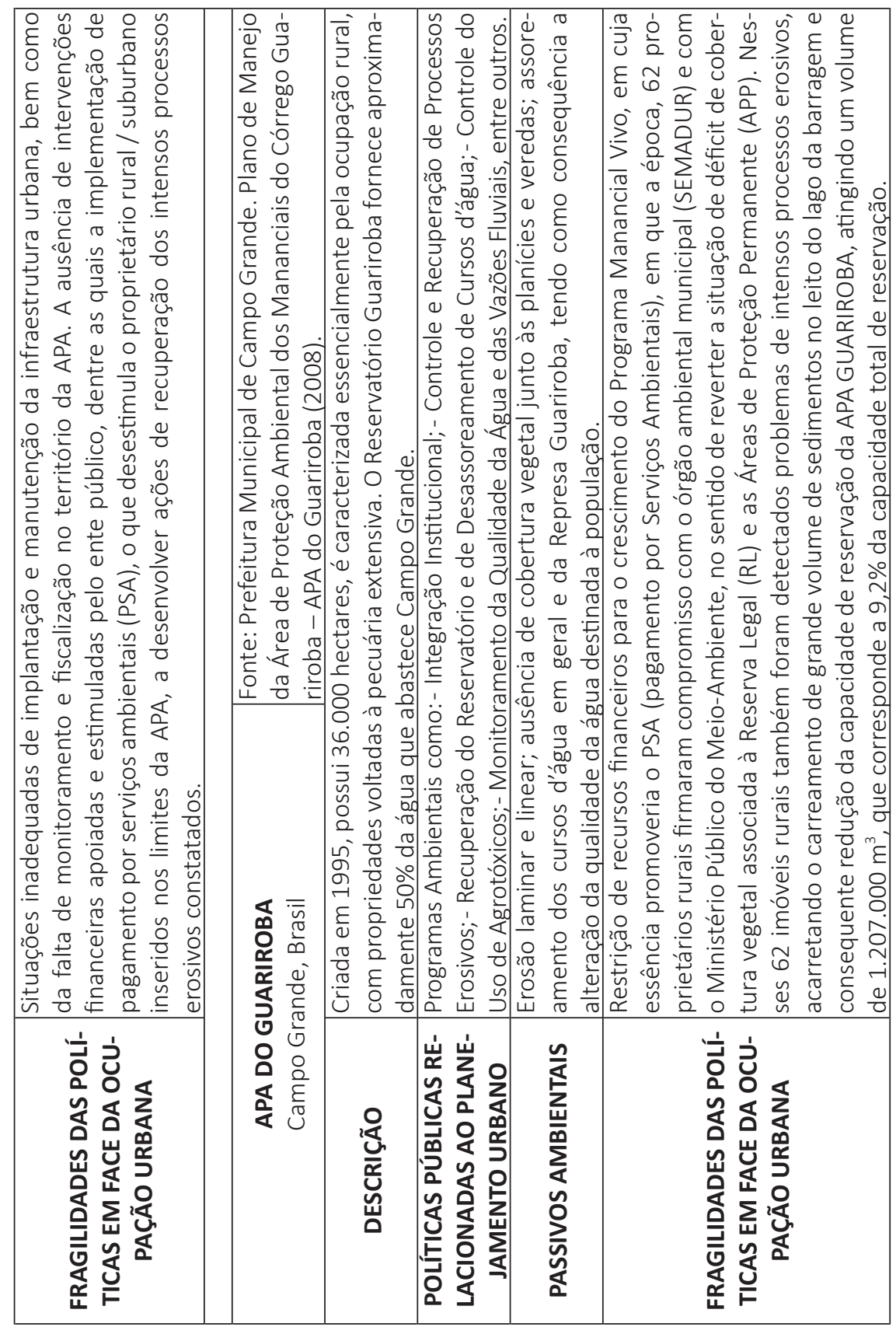




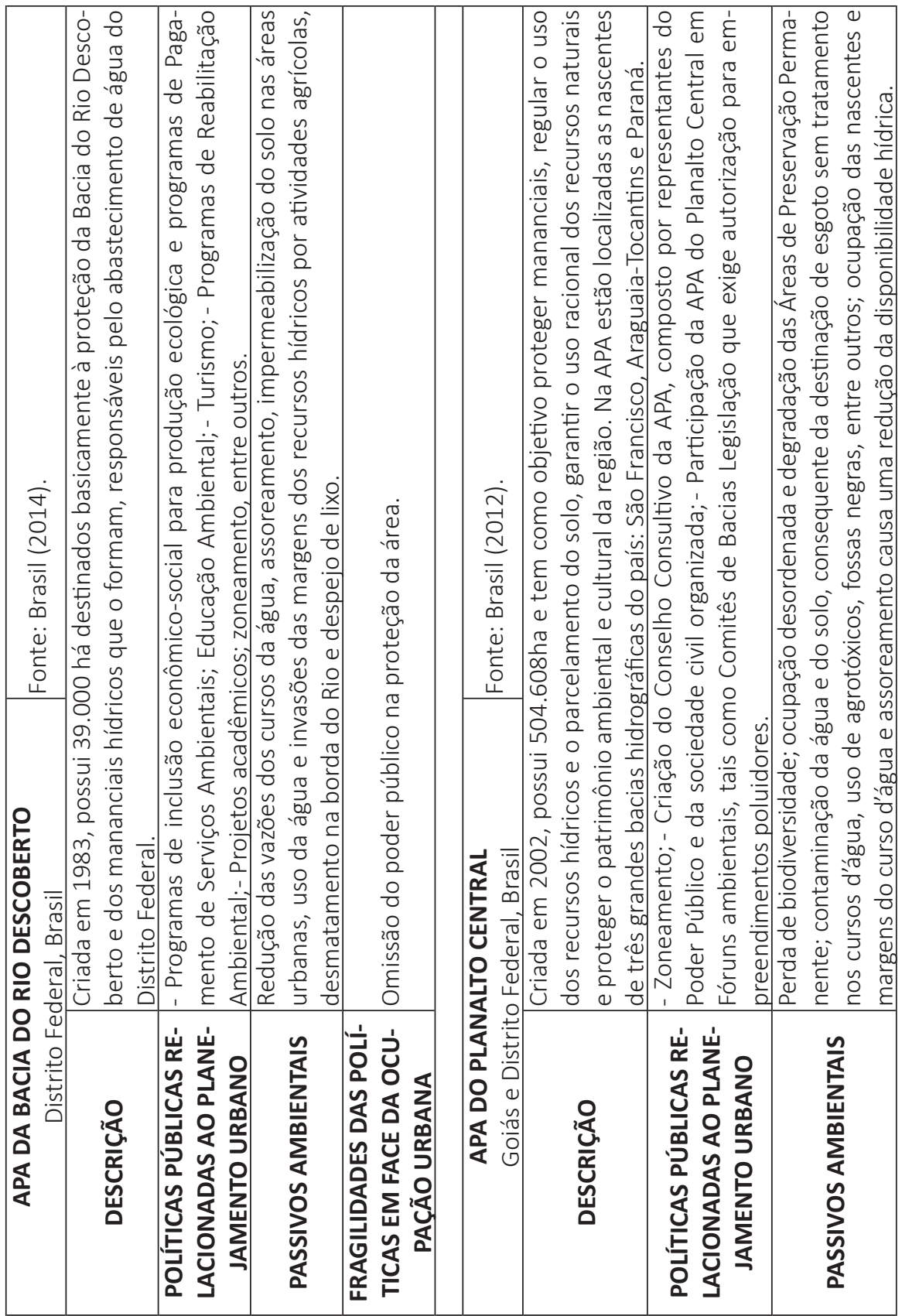




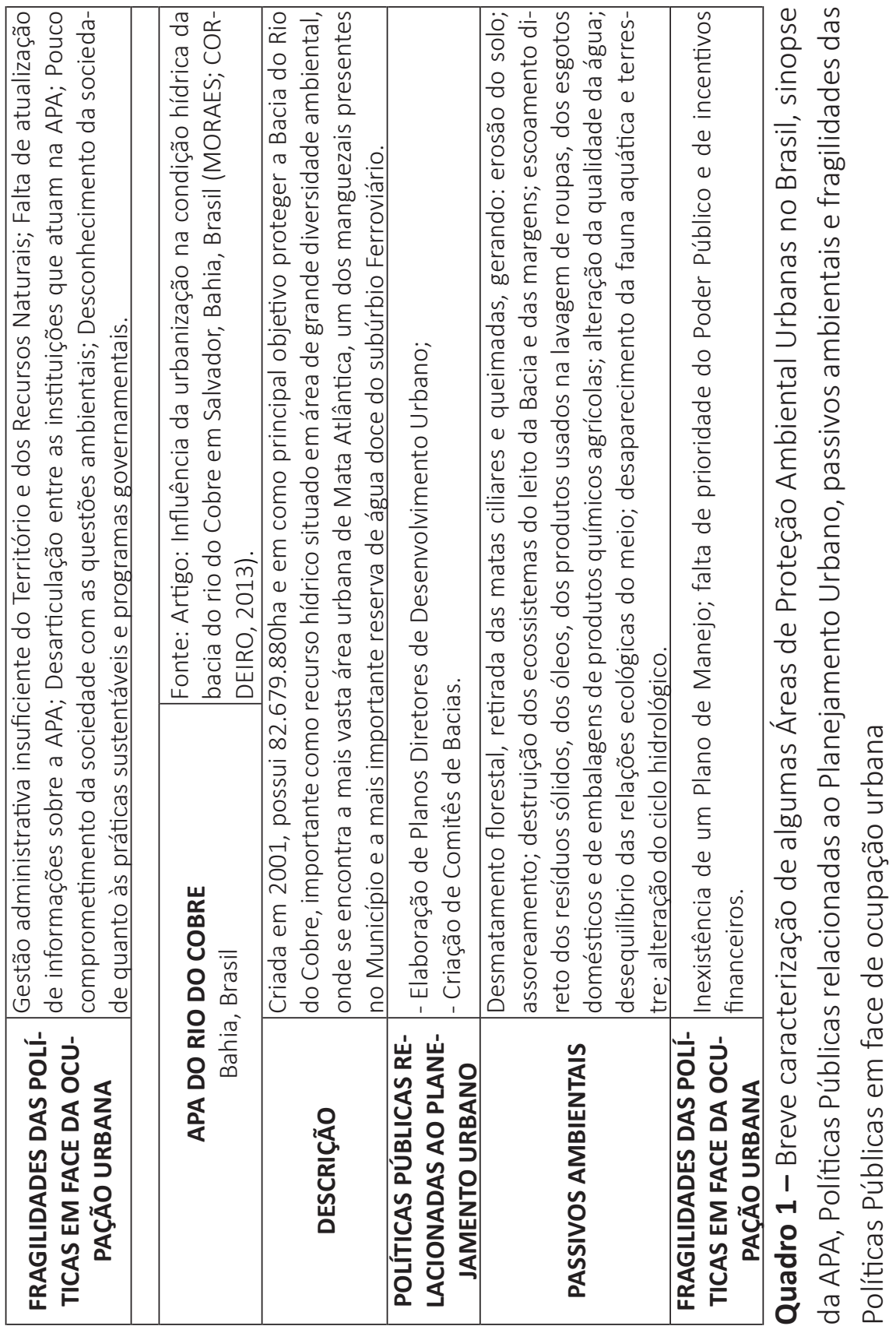


Os dados colhidos e sistematizados nos itens abordados no Quadro 1 permitem identificar problemas ambientais comuns a todas as APAs, em vários aspectos contidos nos tópicos dos passivos ambientais e das fragilidades das políticas públicas, em consequência do aumento demográfico, ocasionados pelos empreendimentos imobiliários, entre outros. Os aspectos comuns referem-se a:

i) situações de intensa degradação ambiental, ocasionada especialmente por supressão da vegetação com o avanço dos empreendimentos imobiliários dentro das APAs, afetando os recursos hídricos;

ii) erosão laminar e linear, ausência de cobertura vegetal junto às planícies e veredas, assoreamento de cursos d'água e nascentes; em geral, inadequadas condições de implantação e manutenção da infraestrutura urbana, bem como falta de monitoramento e fiscalização no território da APA; ausência de intervenções financeiras apoiadas e fomentadas pelo ente público, dentre as quais a implementação de pagamento por serviços ambientais (PSA), o que desestimula os proprietários rurais e urbanos inseridos nos limites das APAs, a desenvolver ações de recuperação dos intensos processos erosivos constatados;

iii) perda de biodiversidade, ocupação desordenada e degradação das Áreas de Preservação Permanente; contaminação da água e do solo com a consequente destinação de esgoto sem tratamento nos cursos d'água, uso de agrotóxicos, fossas negras, entre outros; ocupação das nascentes e margens de cursos d'água e assoreamento, o que causa uma redução da disponibilidade hídrica, bem como a gestão administrativa insuficiente do território e dos recursos naturais; falta de atualização de informações sobre a APA; desarticulação entre as instituições que atuam na APA; pouco comprometimento da sociedade com as questões ambientais, em função do desconhecimento das práticas sustentáveis e programas governamentais; 
iv) com raras exceções, inexistência de um Plano de Manejo corroborado pela falta de prioridade do Poder Público e de incentivos financeiros.

\section{CONSIDERAÇÕES FINAIS}

Constata-se que os objetivos da criação das APAs, especialmente as urbanas, dentre os quais o de garantir a proteção dos ecossistemas e suas diversidades biológicas, disciplinar a ocupação do solo e o de possibilitar o uso sustentável dos recursos naturais (solo, água e vegetação), em sua plenitude, não têm sido atendidos em vários aspectos relacionados às necessidade humanas nas cidades e no seu entorno rural.

A expectativa de pesquisadores e particularmente da sociedade que usufrui dos benefícios provenientes das APAs é que estas possam cumprir o seu papel descrito nos objetivos gerais das unidades, proporcionando bem-estar e qualidade de vida, não impedindo que os serviços ecossistêmicos da unidade de proteção sejam efetivos.

Por outro lado, é importante lembrar a assertiva de que uma grande fração das unidades de conservação no mundo representa os chamados "parques de papel". Esse termo se refere às unidades de conservação que não foram realmente implantadas e têm apenas uma existência virtual, como linhas desenhadas em mapas oficiais.

\section{REFERÊNCIAS}

AB'SABER, A. N. Os domínios de natureza no Brasil: potencialidades paisagísticas. 3. ed. São Paulo: Ateliê Editorial, 2003.

BRASIL. Ministério do Meio Ambiente. Instituto Chico Mendes de Conservação da Biodiversidade. Plano de Manejo da Área de Proteção Ambiental da Bacia do Rio Descoberto. Brasília, DF, 2014.

.Plano de Manejo da Área de Proteção Ambiental do Planalto Central. Brasília, DF: Instituto Chico Mendes de Conservação da Biodiversidade (ICMBio)/Ministério do Meio Ambiente, 2012. 
Políticas Públicas e fragilidades na gestão de Unidades de Conservação Urbanas no Brasil

. Lei n. 9.985, de 18 de julho de 2000. Regulamenta o art. 225, § 1으, incisos I, II, III e VII da Constituição Federal, institui o Sistema Nacional de Unidades de Conservação da Natureza e dá outras providências. Disponível em: <http://www.planalto.gov.br/ccivil_03/leis/L9985.htm>. Acesso em: fev. 2016.

CHAVES, H. M. L.; SANTOS, L. B. dos. Ocupação do solo, fragmentação da paisagem e qualidade da água em uma pequena bacia hidrográfica. Revista Brasileira Engenharia Agrícola e Ambiental, Campina Grande, PB, v. 13, supl. 0, p. 922-930, nov./dez. 2009. http://dx.doi.org/10.1590/ S1415-43662009000700015

COSTA, R. B.; SCARIOT, A. A fragmentação florestal e os recursos genéticos. In: COSTA, R. B. (Org.). Fragmentação florestal e alternativas de desenvolvimento rural na região Centro-Oeste. Campo Grande, MS: UCDB, 2003. p. 53-74.

COSTA, R. B.; LOPES, A.; ZORZ, A. Z.; DINIZ, F.; GOMES, J.; NICACIO, P. R.; FONSECA, F. Fragmentação florestal e reprodução de espécies arbóreas. In: PASA, M. C. (Org.). Múltiplos olhares sobre a biodiversidade. Cuiabá, MT: Carlini \& Caniato Editorial, 2015. p. 9-31.

ELLSTRAND, N. C.; ELAM, D. R. Population genetic consequences of small population size: implication for plant conservation. Annual Review Ecology Systematics, v. 24, p. 217-242, 1993.

ESTADÃO, SÃO PAULO. Desmatamento "formiga" ameaça área de proteção e Billings na zona sul de SP. 23 ago. 2015. Disponível em: <http://sao-paulo. estadao.com.br/noticias/geral,desmatamento-formiga-ameaca-area-deprotecao-e-billings-na-zona-sul-de-sp--imp-,1749061.. Acesso em: 15 dez. 2015.

GUIDUGLI, M. C. Estudos genéticos da espécie florestal Cariniana estrellensis (Raddi) Kuntez: diversidade, sistema de cruzamento e fluxo gênico contemporâneo. 2011. Tese (Doutorado em Ciências) - Faculdade de Medicina de Ribeirão Preto, Universidade de São Paulo, Ribeirão Preto, SP, 2011.

MORAES, L. R. S.; CORDEIRO, M. R. A. Influência da urbanização na condição hídrica da bacia do rio do Cobre em Salvador, Bahia, Brasil. In: CONGRESSO IBÉRICO SOBRE PLANEAMENTO E GESTÃO DA ÁGUA, 8. 2013. p. 914-922. Disponível em: <http://revistas.lis.ulusiada.pt/index.php/8cigpa/article/ view/391/pdf_68>. 
MÜLLICH, E. P. M. Ocupação urbana contemporânea em áreas de proteção ambiental: o caso da Ilha Grande dos Marinheiros em Porto Alegre/RS. 2011. Dissertação (Mestrado em Planejamento Urbano e Regional)- Universidade Federal do Rio Grande do Sul, Porto Alegre, RS, 2011.

PARQUE DA PEDRA BRANCA. Prainha e Grumari. Disponível em: <http:// www.parquepedrabranca.com/p/prainha-e-grumari-belos-recantos.html>. Acesso em: 15 de dezembro de 2015.

PREFEITURA MUNICIPAL DE CAMPO GRANDE. Plano de Manejo da Área de Proteção Ambiental dos Mananciais do Córrego Lajeado-APA do Lajeado. Campo Grande, MS: PMCG, 2012.

. Plano de Manejo da Área de Proteção Ambiental dos Mananciais do Córrego Guariroba - APA do Guariroba. Campo Grande, MS: PMCG, 2008. . Decreto Municipal n. 8.264 de 27 de julho de 2001. Cria a Área de Proteção Ambiental da Bacia do Córrego Ceroula - APA do Ceroula e dá outras providências. Disponível em: <http://www.capital.ms.gov.br/ egov/imagemCanais/file/Apa\%20Ceroula/Legisla\%C3\%A7\%C3\%A3o/3Decreto\%208264-2001_Cria\%20APA\%20Ceroula.pdf>. Acesso em: fev. 2016.

PREFEITURA MUNICIPAL DE SÃO PAULO. Área de Proteção Ambiental Bororé-Colônia. Disponível em: <http://www.prefeitura.sp.gov.br/cidade/ secretarias/meio_ambiente/unid_de_conservacao/apa_bororecolonia/ index.php?p=41963>. Acesso em: 16 dez. 2015.

ROCHA, C. F. D. Biologia da conservação: essências. São Carlos, SP: RIMA, 2006.

SANTOS, R., E.; DONATO, A. M. APA de Grumari: diagnóstico ambiental e alternativas para a sua conservação. Interagir: pensando a extensão, Rio de Janeiro, n. 15, p. 49-55, jan./dez. 2010.

SCHOONHOVEN, L. M.; JERMY, T.; LOON, J. J. A. Insect-plant biology: from physiology to evolution. 1. ed. London: Chapman \& Hall, 1998.

VIANA, V. M.; PINHEIRO, L. A. F. V. Conservação da Biodiversidade em Fragmentos florestais. Série Técnica IPEF, v. 12, n. 32, p. 25-42, dez. 1998. 